Journal of Applied Pharmaceutical Science Vol. 6 (09), pp. 009-017, September, 2016

Available online at http://www.japsonline.com

DOI: $10.7324 / J A P S .2016 .60902$

ISSN 2231-3354 (cc)) BY-NC-SA

\title{
Nano-bio hybrid system for enhanced degradation of cefdinir using Candida sp. SMN04 coated with zero-valent iron nanoparticles
}

\author{
Adikesavan Selvi, Nilanjana Das* \\ School of Bio Sciences and Technology, VIT University, Vellore- 632014, Tamilnadu, India.
}

\begin{tabular}{|c|c|}
\hline ARTICLE INFO & ABSTRACT \\
\hline $\begin{array}{l}\text { Article history: } \\
\text { Received on: } 09 / 06 / 2016 \\
\text { Revised on: } 13 / 07 / 2016 \\
\text { Accepted on: } 04 / 08 / 2016 \\
\text { Available online: } 26 / 09 / 2016\end{array}$ & $\begin{array}{l}\text { The present study evaluates the effect of integrated nano-bio hybrid system involving nanoscale zero-valent iron } \\
\text { (nFe }{ }^{0} \text { ) and yeast Candida sp. SMNO4 on degradation of cefdinir in aqueous medium. The nanoparticle was } \\
\text { chemically synthesised and characterized by atomic force microscopy (AFM), scanning electron microscopy } \\
\text { (SEM), EDAX analysis and particle size analyser. Nano-bio hybrid system was prepared using optimal } \\
\text { concentration }(50 \mathrm{mg} / \mathrm{mL}) \text { of chemically synthesized nFe, which were coated on the surface of yeast cells } \\
\text { without causing any lethal effects to the cell. The survival and viability of the veast cells were monitored by }\end{array}$ \\
\hline $\begin{array}{l}\text { Key words: } \\
\text { Cefdinir, Degradation, } \\
\text { Nano-bio hybrid, Yeast, } \\
\text { Zero-valent iron } \\
\text { nanoparticles. }\end{array}$ & $\begin{array}{l}\text { AFM and SEM images. Cefdinir }(250 \mathrm{mg} / \mathrm{L}) \text { degradation was studied, in both, the individual and hybrid system. } \\
\text { The nano-bio hybrid system showed more effective cefdinir degradation compared to native yeast cell and nano } \\
\text { zero-valent iron solely. The adherence of nanoparticles on the surface of the yeast cells increased the } \\
\text { permeability of the cell membrane, thereby enhancing the entry of cefdinir into the cell. The kinetic data showed } \\
\text { the half-life of cefdinir as } 1.34 \text { days for nano-bio hybrid system, } 3.99 \text { days for } \mathrm{nFe} \mathrm{e}^{0} \text { and } 2.96 \text { days for native } \\
\text { yeast, Candida sp. SMN04 confirming that nano-bio hybrid system reduced the half-life to less than half of the } \\
\text { time taken by the yeast alone. This study signifies the potential efficacy of the nano-bio hybrid system to serve } \\
\text { as an effective remedial tool for the treatment of pharmaceutical wastewater. }\end{array}$ \\
\hline
\end{tabular}

\section{INTRODUCTION}

The presence of pharmaceutical compounds, namely antibiotics in the ecosystem has been known for many years and considered as emerging pollutants. The accumulation and persistence of antibiotics in the environment produce harmful effects even at low concentration in which they are detected (Homem and Santos, 2011). Pharmaceutical industries involved in the production of antibiotics discharge their wastes openly, which contains some quantity of these active compounds that are toxic in nature. Cefdinir is an advanced third generation semisynthetic cephalosporin antibiotic, characterized by a vinyl group at C-3 and a (Z)-2- (2-amino -4 thiazolyl) -2- (hydroxyimino) acetyl moiety at C-7 and used for the treatment of acute respiratory related disorders and mild skin infections. The effluents released from cephalosporin production units are

* Corresponding Author

Email:nilanjana00@ lycos.com reported to release harmful compounds which are resistant to biodegradation, photo-transformation and natural degradation (Wang and Lin, 2012). The presence of high concentration of cephalosporin in the environment leads to very high chemical oxygen demand thus by increasing the toxic strength of the effluent (Duan, 2009). In the last few decades, considerable attention has been given to the treatment of pharmaceutical wastewater. A wide range of physico-chemical methods are being used for the treatment of pharmaceutical wastewaters which are of limited applicability because of the limitations such as inefficiency of remediating high strength wastewater, high operating cost, huge labour requirement, high equipment cost, intervention of toxic byproducts etc. (Homem and Santos, 2011). Bioremediation using yeasts has attracted special interest in the present study since yeast species are found to be adaptable to changing environmental conditions, persist in natural habitats and polluted sites, degrade various toxic and stable organic substances like dyes, pharmaceutical compounds etc. (Recek and Raspor, 1999; Yu and Wen, 2005; Zheng et al., 2010; Selvi and Das, 2014; Yang and Zheng, 2014). 
In recent years, zero-valent iron nanoparticles $\left(\mathrm{nFe}^{0}\right)$ have increasingly been utilized for the remediation of groundwater and hazardous waste treatment. It could be used as a potential degradation tool and reported to have been applied successfully for the degradation of environmental contaminants including $\beta$-lactam antibiotics, a major representative of pharmaceutically active compounds in wastewater (Li et al., 2006; Ghauch et al., 2009; Deng et al., 2013).

Moreover, $\mathrm{Fe}^{0}$ was found to be more effective than $\mathrm{Fe}^{2+}$ as activating agent and potentially more suitable for environmental applications (Ghauch et al., 2009). Because of its super-magnetic property, iron nanoparticles also facilitate easy recovery and reuse and can serve as nanocatalyst making the degradation process more advantageous and economically feasible (Ansari et al., 2009; Li et al., 2013; Xu et al., 2011). In addition, $\mathrm{nFe}^{0}$ is less expensive and can reduce total dissolved solids (TDS) and electrical conductivity (EC) unlike ferrous and ferric salts that generally increase TDS and EC after treatment (Deng et al., 2013).

Previously, we have isolated a yeast, Candida sp. SMN04, which showed an excellent capacity to degrade cefdinir at a concentration of $250 \mathrm{mg} / \mathrm{L}$ (Selvi and Das, 2014; Selvi et al., 2015). The present research is an attempt for enhanced degradation of cefdinir using $\mathrm{nFe}^{0}$ and cefdinir degrading yeast Candida sp. SMN04 together in a nano-bio hybrid system.

\section{MATERIALS AND METHODS}

\section{Chemicals}

Cefdinir (99\% purity) was kindly donated by Orchid Pharmaceuticals, Chennai, India. Dimethyl sulphoxide (DMSO) procured from SRL Chemicals, India Ltd., was used to prepare a stock solution of cefdinir (10 g/L). Sodiumborohydride were of analytical grade and are obtained from Hi-Media India Ltd., SRL Chemicals India Ltd. and Sigma-Aldrich Chemical Co. (USA).

\section{Microorganism and culture}

The cefdinir degrading yeast Candida sp. SMN04 (KF963314.1) isolated from pharmaceutical wastewater was used in this work (Selvi and Das, 2014). The yeast was maintained on yeast extract peptone dextrose (YEPD) slants supplemented with $100 \mathrm{mg} /$ Lof cefdinir. The degradation studies of cefdinir were carried out in mineral broth (MB) containing the following per litre: ammonium sulphate $5.0 \mathrm{~g}$, potassium dihydrogenphosphate $1.0 \mathrm{~g}$, dipotassium hydrogen phosphate $2.0 \mathrm{~g}$, magnesium sulphate $0.5 \mathrm{~g}$, sodium chloride $0.1 \mathrm{~g}$, manganese chloride $0.01 \mathrm{~g}$, ferrous sulphate $0.01 \mathrm{~g}$, sodium molybdate $0.01 \mathrm{~g}, \mathrm{pH} 7.0 \pm 0.2$.

\section{Nano scale zero-valent iron synthesis $\left(\mathrm{nFe}^{0}\right)$}

$\mathrm{nFe}^{0}$ particles were synthesised following the method of Sun et al. (2007) with minor modifications. Equal volumes of $0.94 \mathrm{M} \mathrm{NaBH}$ and $0.18 \mathrm{M} \mathrm{FeCl}_{3}$ were mixed thoroughly and was slowly added drop-wise into IM sodium borohydride solution with vigorous stirring $(\sim 400 \quad \mathrm{rpm})$. The solution turned black immediately due to formation of nanoparticulate iron. The formed iron nanoparticles were harvested using vacuum filtration through $0.2 \mu \mathrm{m}$ filter paper. The synthesized zero-valent iron particles were then washed several times with deionized (DI) water and ethanol before use or stored in water containing $5 \%$ ethanol.

$$
4 \mathrm{Fe}_{(a q)}^{3+}+3 \mathrm{BH}_{4}+9 \mathrm{H}_{2} \mathrm{O} \rightarrow 4 \mathrm{Fe}_{(s)}^{0}+3 \mathrm{H}_{2} \mathrm{BO}_{3}+12 \mathrm{H}_{(a q)}^{+}+6 \mathrm{H}_{2(\mathrm{~g})}(1)
$$

\section{Characterization of $\mathrm{nFe}^{0}$ $X R D$}

The XRD patterns were recorded to study the structural properties of the synthesised $\mathrm{nFe}^{0}$ particles by $\theta-2 \theta$ method of $\mathrm{x}$ ray diffraction (XRD) with a $\mathrm{Cu} \mathrm{K} \alpha_{1}(\lambda=0.15406 \mathrm{~nm})$ source at 40 $\mathrm{kV}$ and $30 \mathrm{~mA}$ using multipurpose $\mathrm{x}$-ray diffractometer (Bruker D8 Advance, Germany). The crystalline size of the particles was calculated from the Debye- Scherrer equation as follows:

$$
d=\frac{0.89 \lambda}{\beta \cos \theta}
$$

where, $d$ is the mean size of the ordered (crystalline) domains, $\lambda$ is the $\mathrm{x}$-ray wavelength, $0.154 ; \beta$ is the line broadening at half the maximum intensity (full-width at half-maximum (FWHM)) and $\theta$ is the Bragg angle.

\section{AFM, SEM and EDAX}

The morphological characterization of the synthesised $\mathrm{nFe}^{0}$ was carried out using atomic force microscope (AFM; Nanosurf, Switzerland; Model: easyScan2) and scanning electron microscope (EVO series-MA15 SEM). EDAX analysis was carried out by SEM coupled with EDAX-EVO-MA15-SEMOxford instruments.

\section{Particle size and size distribution}

The particle size and its distribution were determined using particle size analyser (Horiba scientific SZ-100). A calibration program provided by the instrument manufacturer was used to calculate the particle size distribution (PSD) from the attenuation spectra.

\section{Effect of $\mathrm{nFe}^{0}$ on the growth of strain SMN04}

To study the effect of $\mathrm{nFe}^{0}$ on growth of the yeast, Candida sp. SMN04, agar well diffusion method was followed with various concentration of $\mathrm{nFe}^{0}$ ranging from 5-100 $\mathrm{mg} / \mathrm{mL} \mathrm{nFe}^{0}$ was added onto the lawn culture of the yeast streaked on YEPD agar plate. The test plates were incubated for 2 days at $30{ }^{\circ} \mathrm{C}$ and $120 \mathrm{rpm}$. Zone of inhibition around the wells were indicative of growth inhibition. The least concentration which, showed inhibition was taken as minimal inhibitory concentration (MIC). The test was supported with MIC assay in broth cultures and the cell dry weight was monitored regularly. 


\section{Development of nano-bio hybrid system}

Nano-bio hybrid system was developed following the method of Li et al. (2013). Yeast cells were grown in YEPD broth until the mid-exponential growth phase and harvested by centrifugation at $8400 \times \mathrm{g}$ for $10 \mathrm{~min}$.

The cell pellets were washed twice with phosphate buffer and re-suspended back in YEPD at a concentration of $3 \mathrm{~g} / \mathrm{L}$ of cell dry weight. $10 \mathrm{~mL}$ of the suspension containing $50 \mathrm{mg}$ of $\mathrm{nFe}^{0}$ per millilitre of water was mixed with $100 \mathrm{~mL}$ of the cell suspension in YEPD broth. The ratio of mass of nanoparticles to yeast biomass was $3.0 \mathrm{w} / \mathrm{w}$. At this ratio, nanoparticles were sufficient enough to coat the yeast cells. The $\mathrm{nFe}^{0}$ coated yeast cells termed as nano-bio hybrid system were visualized by AFM and SEM analysis.

\section{Cefdinir degradation assay}

Batch degradation studies were carried out in $100 \mathrm{~mL}$ of MB containing cefdinir at a final concentration of $250 \mathrm{mg} / \mathrm{L}$ in 250 $\mathrm{mL}$ Erlenmeyer flask incubated on a rotary shaker at $120 \mathrm{rpm}$ and $30^{\circ} \mathrm{C}$. Degradation experiments employed the following treatments in MB containing cefdinir, which include (1) nano-coated yeast cells (nano-bio hybrid degradation), (2) native yeast cells (biodegradation), (3) $\mathrm{nFe}^{0}$ (nanodegradation) and (4) uninoculated control.

These treatments were used to compare the efficiency of nano-bio hybrid system and native yeast cells. The experiments were run for 6 days under aerobic conditions. The supernatant was collected at regular intervals and residual cefdinir was analysed by UV-spectrophotometric analysis (Shimadzu UV-2450), following the method of Cabri et al. (2006) with minor modifications. The residual cefdinir concentration was calculated using the formula given below,

$$
\text { Residual cefdinir concentration }(\%)=\frac{C_{i}-C_{f}}{C_{0}} \times 100
$$

The obtained degradation data were fitted with pseudo-first order reaction kinetics (Capellos and Bielski, 1972) for the calculation of half-life and degradation rate constant using the following equations:

$$
\begin{aligned}
& C_{t}=C_{0} \cdot e^{-k^{\prime} t} \\
& t_{1 / 2}=\ln 0.5 /-k^{\prime}
\end{aligned}
$$

where, $\mathrm{C}_{0}$ is the initial concentration of cefdinir in the medium, $C_{t}$ is the concentration of cefdinir at time ' $t$ ', $k$ ' is the degradation rate constant, $\mathrm{t}_{1 / 2}$ is the biodegradation half-life period of cefdinir.

\section{Enzyme analysis}

To study the enzymatic response of native and nanocoated yeast cells, activities of various enzymes viz. $\beta$-lactamase (Wayne, 2002), NADPH reductase (Kappeli et al., 1982), amylase
(Yalchin and Corbaci, 2013), manganese peroxidase (Hussaini et al., 2011) were assayed following the standard protocols collecting the samples at regular time intervals. The crude extracts from yeast cells grown in MB without cefdinir were used as controls. One unit is equivalent to that amount of enzyme required to catalyze the $1.0 \mathrm{mg}$ of substrate per minute under standard assay conditions.

\section{RESULTS AND DISCUSSION}

\section{Characterization of $\mathrm{nFe}^{0}$}

X-ray diffraction (XRD) pattern of chemically synthesized zerovalent iron nanoparticlesis shown in Fig. 1. The diffraction peaks of $\mathrm{nFe}^{0}$ exhibited at $2 \theta=44.6^{\circ}, 64.9^{\circ}$ and $82.2^{\circ}$ which are corresponding to the (111), (200) and (211) diffraction plane of cubic structured $\mathrm{Fe}$ phase (JCPDS 87-0721). The diffraction peaks are in good agreement with an earlier report by Dickinson and Scott (2010).

The estimated crystalline sizes using Scherrer's formula for the $\mathrm{nFe}^{0}$ was found to be $31.7 \mathrm{~nm}$. The full width half maximum (FWHM) of 0.270 and $\theta$ value of 0.389 (in radians) corresponding to the high intensity peak of the nanomaterial was observed.

The surface morphology of the synthesized nanoparticles was examined by atomic force microscope and scanning electron microscope. The AFM and SEM micrographs of $\mathrm{nFe}^{0}$ powder was shown in Fig. 2(a,b). The microscopic studies revealed the synthesized zero-valent iron nanoparticles were of spherical in shape. Similar findings were reported by Sun et al.(2007). The corresponding particle size distribution of $\mathrm{nFe}^{0}$ revealed that the average particle diameter of the synthesized $\mathrm{nFe}^{0}$ was in the nanometer range (10-30 nm). Toxicity concerns are often based on its large size and mobility, whereas $\mathrm{nFe}^{0}$ used in the present study is of small size (crystalline size-31.7 nm), which prevents their dispersion and persistence in the environment thus making the degradation process eco-friendly (Wiesner et al., 2006).

The intensity weighed particle size distribution histogram is presented in Fig. 2(c). Another study conducted by Ponder $e t$ al. (2000) gave an estimation of the average nano scale iron particle diameter as 10-30 nm. Sun et al.(2007) stated that the particle size of iron nanoparticles ranged from tens to hundreds of nanometers. The differences in the particle sizes obtained using the microscopic technique were due to differences in sample preparation and due to the polydispersity of the sample which will depend upon the particle numbers, volume, mass or optical property (Vimala et al., 2014).

The EDAX spectrum of $\mathrm{nFe}^{0}$ showed a single strong peak at $0.7 \mathrm{KeV}$ corresponding to $\mathrm{Fe}$ element, therefore confirming the synthesized nanoparticle was free from other impurities (Fig. 2d). These characterization results confirmed that the $\mathrm{nFe}^{0}$ formed was in nanosize and hence these nanoparticles were used as nanocatalyst for cefdinir degradation experiments in mineral medium. 


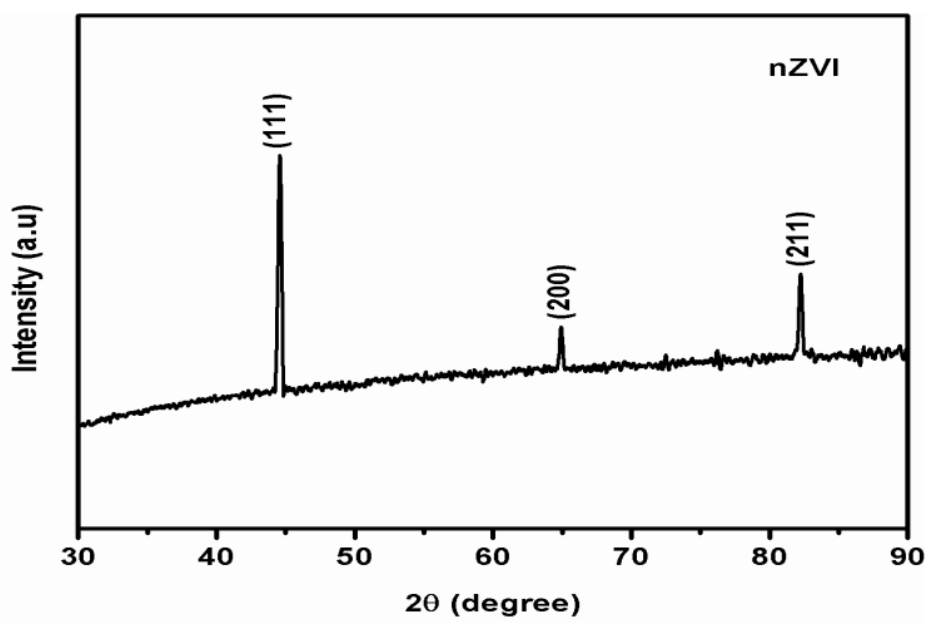

Fig. 1: X-Ray diffraction pattern of $\mathrm{nFe}^{0}$.
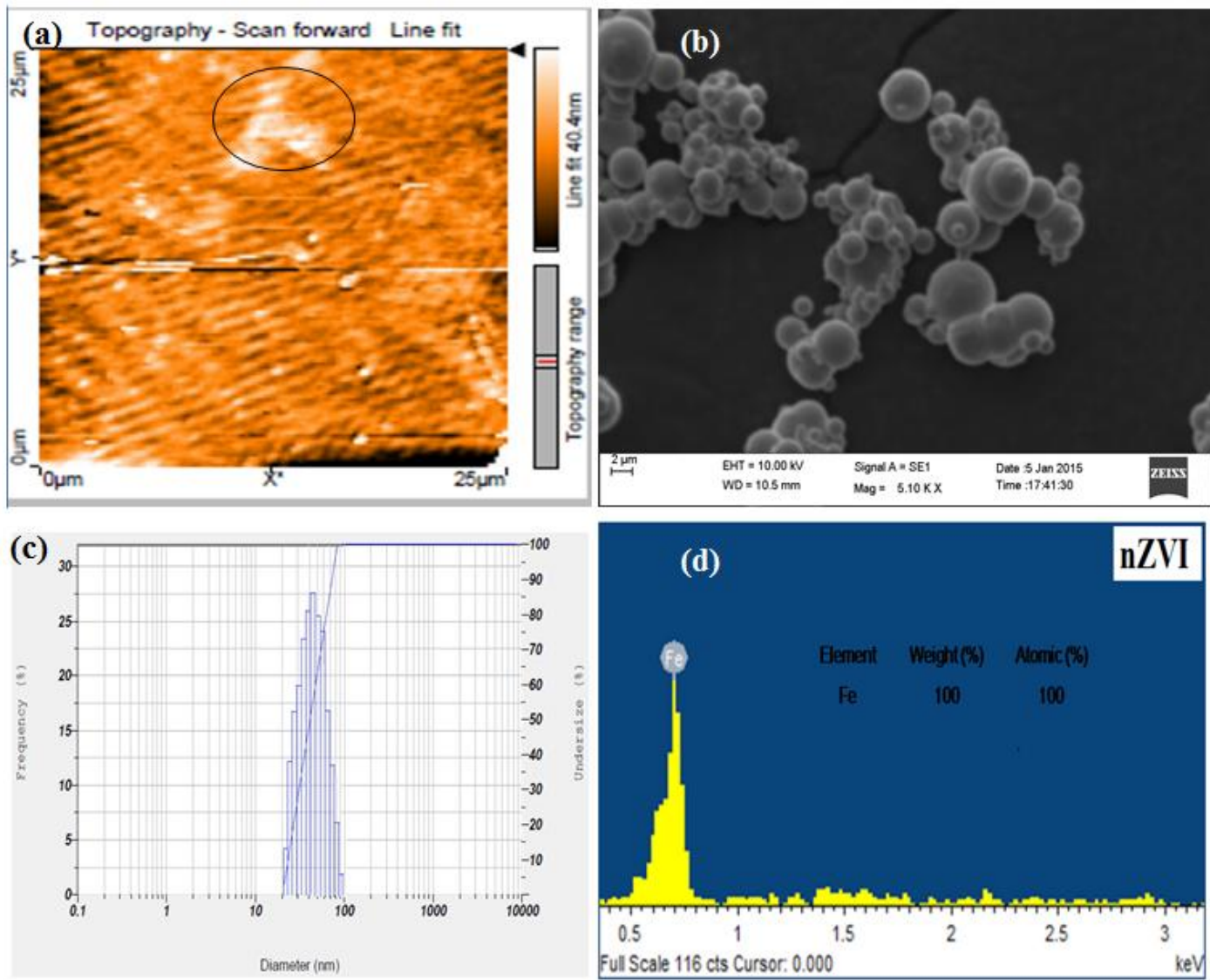

Fig. 2: Characterization studies of $\mathrm{nFe}^{0}$. (a)AFM image; (b) SEM image; (c) histogram showing particle size distribution and (d) EDAX spectrum.

\section{Effect of $\mathrm{nFe}^{0}$ on growth of Candida sp. SMN04}

In general, nanoparticles exert toxic effects on microbes by disrupting the cell membranes, increasing the membrane permeability, interrupting the energy transduction, producing reactive oxygen species etc. (Diao and Yao, 2009; Li et al., 2010). The obtained results showed that, the yeast cells showed the positive effect of growth until $50 \mathrm{mg} / \mathrm{mL}$ concentration of
$\mathrm{nFe}^{0}$ (Figure not shown). Above this concentration, the yeast cells showed poor or no growth, indicating the cell damage and microcidal activity of $\mathrm{nFe}^{0}$ and complete inhibition of cell growth was noticed at $75 \mathrm{mg} / \mathrm{mL}$ of $\mathrm{nFe}^{0}$, therefore this concentration was noted as MIC for Candida sp. SMN04. Hence, concentration of $50 \mathrm{mg} / \mathrm{mL}$ was used for yeast coating to form a nano-bio hybrid system for cefdinir degradation experiments. 


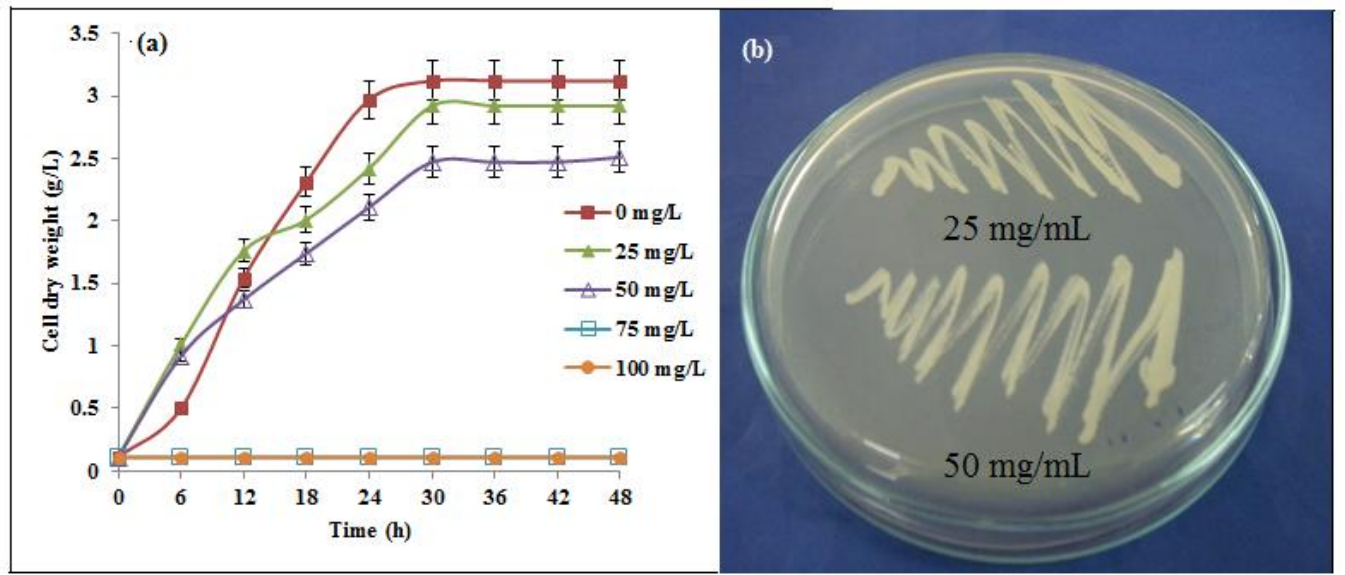

Fig. 3: Survival assay of Candida sp. SMN04 grown with $\mathrm{nFe}^{0}$ (a) Growth curves of Candida sp. SMN04 grown at various concentrations of $\mathrm{nFe}{ }^{0}$, (b)Survival assay of strain SMN04 grown in presence of $\mathrm{nFe}^{0}$ at 25 and $50 \mathrm{mg} / \mathrm{mL}$

Thus, MIC \& survival assay was performed to determine the lowest concentration of $\mathrm{nFe}^{0}$ that inhibits the visible growth of the microbe in an overnight culture. After the preliminary experiments of MIC determination, survival assay of the yeast cells were demonstrated in YEPD broth (Fig. 3a) and YEPD plate (Fig. 3b) containing $\mathrm{nFe}^{0}$ concentration below its MIC value. The results were analysed in terms of cell dry weight and cell growth $(\mathrm{g} / \mathrm{L})$ respectively. Fig. 3(a) explains the growth curve of the yeast strain with various concentrations of $\mathrm{nFe}^{0}$ ranging from $0-100$ $\mathrm{mg} / \mathrm{mL}$, where the maximum cell dry weight was observed in the medium containing no $\mathrm{nFe}^{0}$, indicating an inhibitory effect of $\mathrm{nFe}^{0}$ on yeast growth. A significant amount of biomass was produced in the medium containing 25 and $50 \mathrm{mg} / \mathrm{mL}$ of $\mathrm{nFe}^{0}$. The growth of the yeast colonies on YEPD plates showed that the yeast cells could tolerate up to $50 \mathrm{mg} / \mathrm{mL}$ of $\mathrm{nFe}^{0}$. When the concentration of $\mathrm{nFe}^{0}$ was increased up to $75 \mathrm{mg} / \mathrm{mL}$ and above, yeast growth was found to be completely inhibited (Fig. 3a). The results of this experiment were supported with yeast survival assay on YEPD plates (Fig. 3b). From the results, it was implied that $\mathrm{nFe}^{0}$ at a concentration of $50 \mathrm{mg} / \mathrm{mL}$ was tolerated by the yeast with no lethal effects or cell damage. Therefore, $50 \mathrm{mg} / \mathrm{mL}$ concentration of $n \mathrm{Fe}^{0}$ was fixed as the optimum concentration for yeast coating.

\section{Nano-bio hybrid system}

The images of atomic force micrographs (AFM) of the native cells and yeast cells with $\mathrm{nFe}^{0}$ (nano-bio hybrid system) are presented in Fig. 4, which shows both topography (1a-d) and deflection (2a-d) images. As observed, the native cells showed normal morphology with oval-shaped cells with smooth and intact cell wall structure (Fig. 4a).

The AFM images of the nano-bio hybrid system showed increased surface area due to the adsorption of $\mathrm{nFe}^{0}$ nanoparticles onto the surface of the yeast cells. At lowest concentrations of $\mathrm{nFe}^{0}$, i.e., $25 \mathrm{mg} / \mathrm{mL}$, even though the nanoparticles were attached to the cell surface, the yeast was in a growing phase with intact cell wall structure (Fig. 4b). On further increasing the concentration of $\mathrm{nFe}^{0}$ to $50 \mathrm{mg} / \mathrm{mL}$, the yeast cells were still found in growing condition, which indicated that the adsorption of zerovalent nanoparticles did not show any negative impact on the growth of yeast cells (Fig. 4c). In both cases, the yeast cells were viable in nature as evident from the presence of intact cell structures. This implied that the concentration of 25 and $50 \mathrm{mg} / \mathrm{mL}$ were not lethal to the yeast strain SMN04. According to Lee et al. (2008), formation of oxide layer by iron nanoparticles can decrease the toxicity of iron nanoparticles towards microbial cells supporting their survival. Kim et al. (2010) also reported that inactivation of microbial cells by iron nanoparticles was less under aerated conditions than de-aereated environments. The yeast cells grown in $75 \mathrm{mg} / \mathrm{mL}$ of $\mathrm{nFe}^{0}$ showed the absence of proper cell wall structure which might be due to the rupture of the cell because of the increased concentration of $\mathrm{nFe}^{0}$ (Fig. 4d). These observations suggested that accumulation of the nanoparticles by the yeast cell was directly proportional to the concentration of the nanoparticle. Since, at $\mathrm{nFe}^{0}$ concentration of $50 \mathrm{mg} / \mathrm{mL}$ in the growth medium of the yeast strain SMN04 could stimulate the coating of $\mathrm{nFe}^{0}$ nanoparticles without causing any lethal effect to the cell, this concentration was considered optimum for the development of a nano-bio hybrid system, which will induce membrane permeabilization to facilitate the entry of cefdinir into the cell. These findings were also reported by other workers in case of pollutant removal (Ansari et al., 2009; Diao and Yao, 2009; Li et al., 2010). Figure 5 shows the scanning electron micrographs of the surfaces of the native yeast cells and $\mathrm{nFe}^{0}$-yeast hybrid system. In Fig. 5(a), the native cells had normal ovoid cell morphology, whereas, the yeast cells with $\mathrm{nFe}^{0}$ (Fig. 5b) clearly showed that the $\mathrm{nFe}^{0}$ particles were efficiently assembled on the surface of the yeast cell. In this condition, the yeast cells were alive and in actively dividing phase with budding cells. The SEM images revealed that there were no morphological distortions in case of control and nano-hybrid yeast cells. Fig.5(c) shows that the yeast cells recovered from the stationary phase of cefdinir degradation. Recently, Li et al.(2013) reported the same findings while demonstrating carbazole biodegradation using Sphingomonas cells $/ \mathrm{Fe}_{3} \mathrm{O}_{4}$ nanoparticles. 

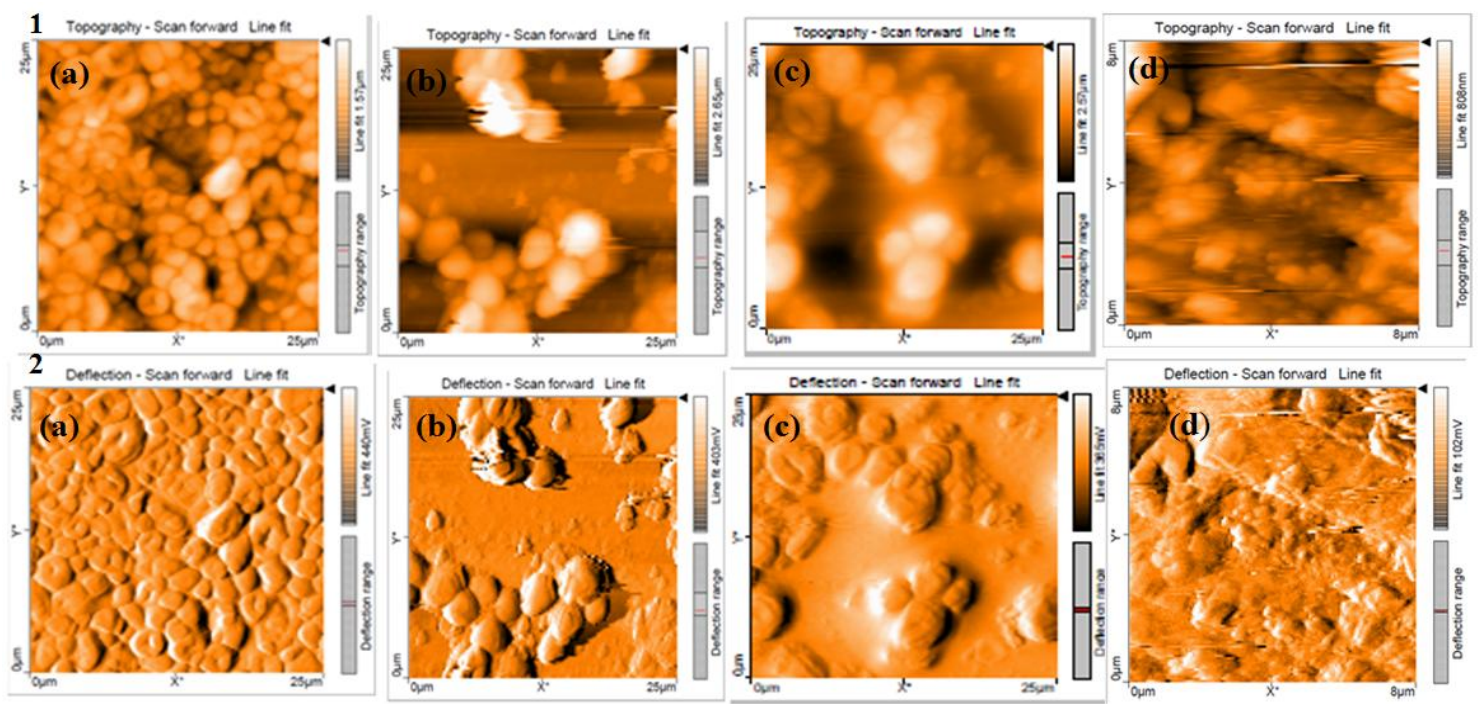

Fig. 4: AFM images of Candida sp. SMN04. (a) Native yeast cells; (b) yeast cells grown with $25 \mathrm{mg} / \mathrm{mL}$ of $\mathrm{nFe} \mathrm{p}^{0}$; (c) yeast cells grown with $50 \mathrm{mg} / \mathrm{mL}$ of $\mathrm{nFe} \mathrm{e}^{0}$; (d) yeast cells grown with $75 \mathrm{mg} / \mathrm{mL}$ of $\mathrm{nFe}^{0}$ showing topography (1) and deflection (2) of each image.
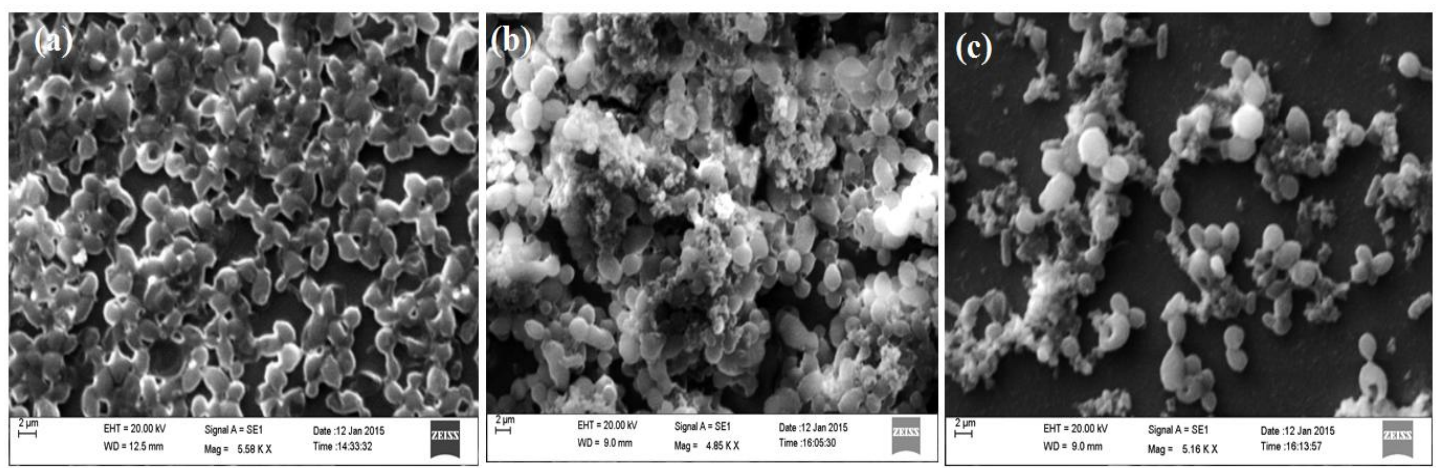

Fig. 5: SEM Images showing (a) Native yeast cell; (b) nano-bio hybrid $\mathrm{nFe}^{0}$ coated yeast cells at optimal concentration of $50 \mathrm{mg} / \mathrm{mL}$ and (c) cefdinir-interacted nano-bio hybrid cells recovered from stationary phase.

\section{Degradation of cefdinirusing $\mathrm{nFe}^{0}$ and nano-bio hybrid system}

Fig. 6(a) compares the degradation of cefdinir in MB with the native yeast cells, $\mathrm{nFe}^{0}$ as well as nano coated yeast as nano-bio hybrid system. The results showed that the amount of residual cefdinir was significantly less in the case of nano-bio hybrid system. The percent removal of cefdinir was found to be $84 \%$ in case of native yeast cells and $73 \%$ in case of $\mathrm{nFe}^{0}$ particles within 6 days of treatment, whereas, in the culture of the nano-bio hybrid system, $91 \%$ removal was observed within a period of 2.68 days. The faster cefdinir removal might be due to synergistic effect of the nano-bio hybrid system. However, after the measurement of residual concentration of cefdinir in various treatments after 10 days, it was found that complete removal of cefdinir was achieved by nano-bio hybrid system (data not shown). The enhanced entry of cefdinir into the yeast cells occurred due to the increased permeability as a results of $\mathrm{nFe}^{0}$ coating on yeast cells, which could positively influence the rate of cefdinir utilization by the yeast. Ghauch et al. (2009) reported the complete removal of amoxicillin and ampicillin using $\mathrm{nFe}^{0}$ particles with final antibiotic concentration of $20 \mathrm{mg} / \mathrm{L}$. Our study reports the complete removal of cefdinir using nano-bio hybrid system with final concentration of $250 \mathrm{mg} / \mathrm{L}$. The increased permeability of the yeast cells due to $\mathrm{nFe}^{0}$ adsorption on their surface might be another factor, which could have positively influenced faster cefdinir degradation. This adsorption of nanoparticles with yeast cells facilitates easy transport of cefdinir into the intracellular matrix through a transmembrane system, leading to the enhanced entry of the pollutant (Grigoriev, 2002; Ansari et al., 2009). Additionally, $\mathrm{nFe}^{0}$ can be easily recovered and reused from the medium using "magnetic separation" technique, which is a low-cost, simple and highly reliable. Xu et al. (2011) studied the recovery of $\mathrm{Fe}_{3} \mathrm{O}_{4}$ magnetic nanoparticles from the harvested microalgal biomass and maintained the same microalgal recovery efficiency as the newly synthesized ones after five times of reuse. To understand the reaction kinetics of cefdinir removal, the degradation data were fitted to pseudo-first order kinetic model (Fig. 6b). The degradation rate constant and half-life were calculated from the kinetic plot and presented in Table 1. The half-life of cefdinir 
degradation was 2.97 days (almost equal to $71.2 \mathrm{~h}$ ) for the yeast Candida sp. SMN04, which was further reduced in the case of the nano-bio hybrid system being 1.34 days (almost equals to $32 \mathrm{~h}$ ). The results suggested that, the degradation of cefdinir by the nanobio hybrid system proved to be more efficient than the individual systems which could bring down the half-life to more than half of the value as shown by the individual yeast.
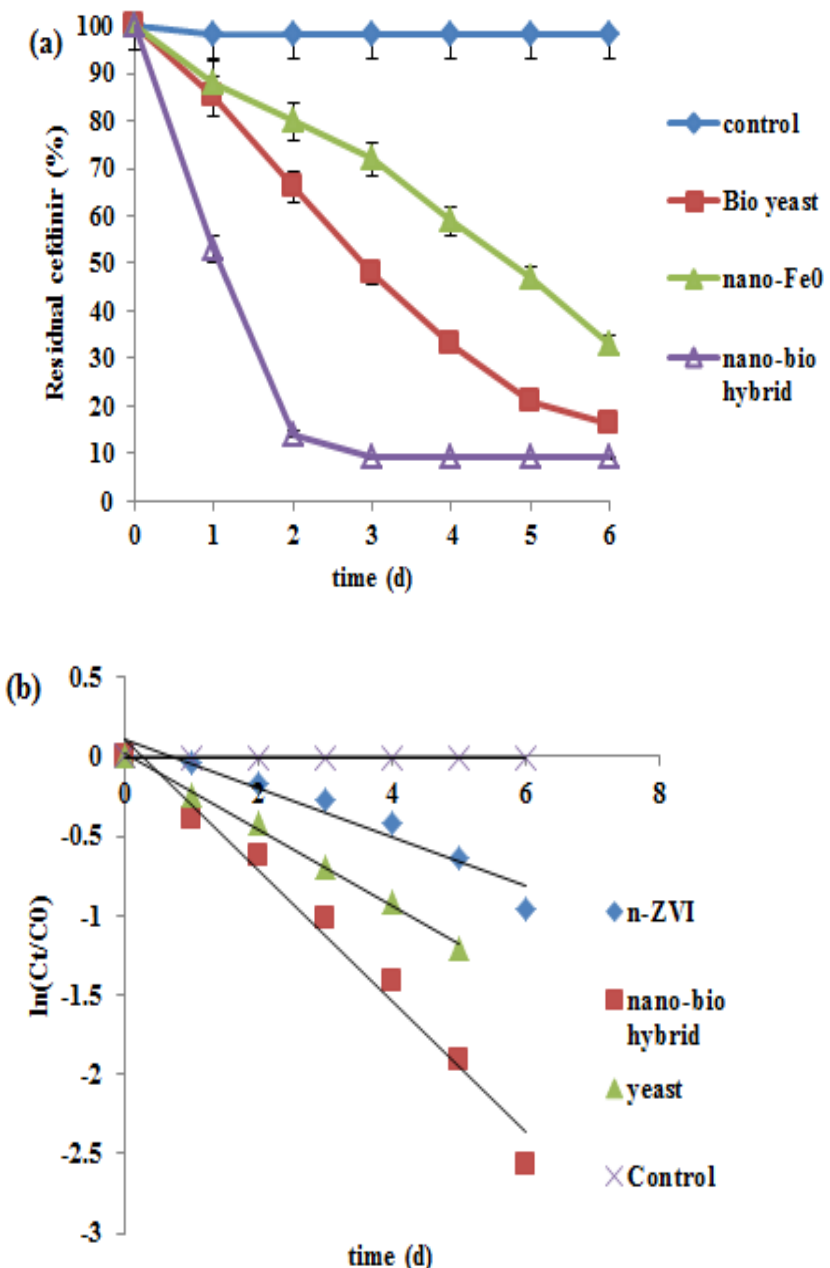

Fig. 6: Cefdinir degradation in mineral medium. (a) Residual cefdinir percentage in the culture medium treated with various degradation agents; and (b) pseudo first-order kinetic plot of cefdinir degradation by various treatments.

Table 1: Comparision of kinetic parameters of cefdinir degradation in various systems.

\begin{tabular}{lcc}
\hline Treatments & $\begin{array}{c}\text { Rate constants; K per } \\
\text { day }\end{array}$ & $\begin{array}{c}\text { Half life; } \mathbf{T}_{\mathbf{1 / 2}} \\
\text { (days) }\end{array}$ \\
\hline Control & 0.0013 & 533.19 \\
$\mathrm{nFe}^{0}$ & 0.1736 & 3.99 \\
Candida sp. SMN04 & 0.2335 & 2.97 \\
Nano-bio hybrid & 0.5171 & 1.34 \\
\hline
\end{tabular}

\section{Enzyme analysis}

The role of degradative enzymes in cefdinir degradation using native yeast cells and nano-bio hybrid system was evaluated through standard enzyme analysis. In the present study, activity of $\beta$-lactamase (Fig. 7a), NADPH reductase, amylase, manganese peroxidase was tested (Fig. 7b). The antibiotic activity of cefdinir was tested growing E.coli in the test plates where, a zone of no growth around the well was noted. Cefdinir degraded products collected at the end of day 1 was tested on the same organism where no inhibitory zone of growth was found which confirmed the loss of antibiotic property demonstrating the role of the enzyme $\beta$-lactamase during cefdinir degradation. This is considered as one of the vital steps in the antibiotic degradation process (Okamoto et al., 1996; Cabri et al., 2006; Mashelkar and Renapurkar, 2010). A rapid rupture of $\beta$-lactam ring within $40 \mathrm{~min}$ of treatment with nano scale iron particles was reported by Ghauch et al. (2009) during removal of $\beta$-lactam antibiotics from water. The enhanced activities of other three enzymes viz., NADPH reductase, amylase, manganese peroxidase were also noted in nano-bio hybrid system compared to native yeast cells. Enhanced activity of enzymes immobilized on nanoparticles was reported in other studies (Dyal et al., 2003; Li et al., 2007; Song et al., 2012).
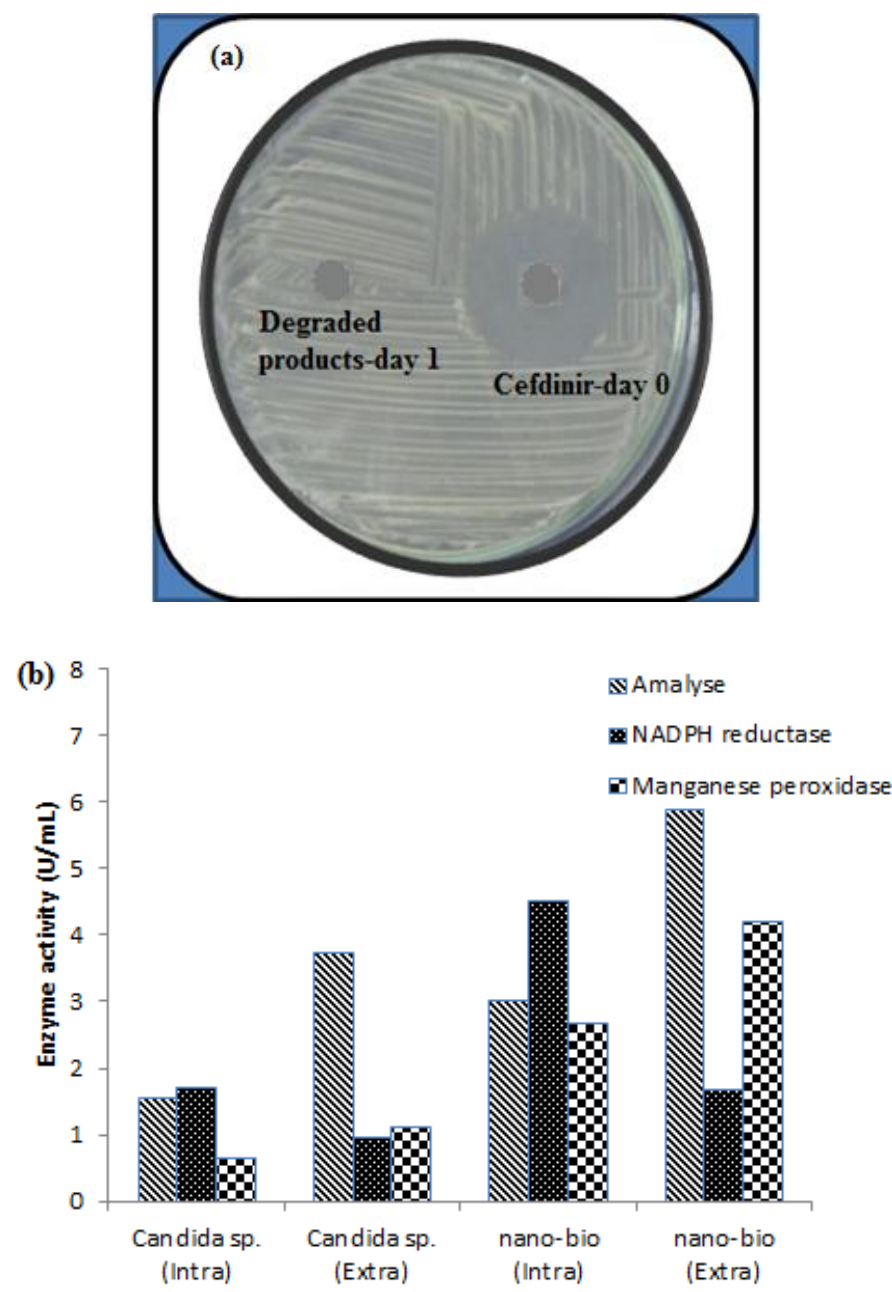

Fig. 7: Enzyme assays involved in cefdinir degradation. (a) Demonstatation of loss of antibiotic activity ( $\beta$-lactamase) on day 0 (cefdinir) and day 1 degraded products after degradation; and (b) Other degradative enzymes in intra and extracellualr fractions of native Candida sp. SMN04 and nano-bio hybrid systems. 


\section{CONCLUSION}

The present research showed the applicability of a novel nano-bio hybrid system using $\mathrm{nFe}^{0}$ coated on Candida sp. SMN04 for enhanced degradation of cefdinir. Experiments conducted in batch mode revealed that the degradation of cefdinir by nano-bio hybrid system was more than the individual systems. The coated yeast showed more activity than the non-coated ones. The concentration of $\mathrm{nFe}^{0}$ for coating on the yeast was optimized. The nano-bio hybrid system showed $91 \%$ degradation of cefdinir at concentration of $250 \mathrm{mg} / \mathrm{Lw}$ ithin two and half days, which was a remarkable decrease in time compared to the results reported earlier.

Further, the involvement of major enzyme $\beta$-lactamase along with other enzymes was also noted during cefdinir degradation. The enhanced activity of the enzymes may be possibly due to the immobilization of both intracellular and extracellular degradative enzymes onto $\mathrm{nFe}^{0}$ particles. Enhanced cefdinir degradation might have occurred through an integrated approach of nano-bio hybrid system involving $\mathrm{nFe}^{0}$ and Candida sp. SMN04 in aqueous medium may serve as an effective remediation tool for the treatment of pharmaceutical wastewater containing cephalosporin antibiotics.

\section{ACKNOWLEDGEMENTS}

Financial support and sponsorship: The authors are thankful to the Nanotechnology Lab and VIT-SAF Lab, SAS, VIT university. We also like to thank SEM Lab, SBST, VIT University for the instrumental services. The financial support and laboratory facility provided by VIT University, Vellore are duly acknowledged.

\section{Financial support and sponsorship: Nil.}

Conflict of Interests: There are no conflicts of interest.

\section{REFERENCES}

Ansari F, GrigorievP, Libor S, Tithill IE, Ramsden JJ. DBT degradation enhancement by decorating Rhodococcuserythropolis IGST8 with magnetic $\mathrm{Fe}_{3} \mathrm{O}_{4}$ nanoparticles. BiotechnolBioeng., 2009;102:15051512.

Cabri W, GhettiP, AlpegianiM, PozziG, Justo-ErbezA, PerezMartınezJI, Villalo'n-RubioR, Monedero-PeralesMC,MunozRuizA.Cefdinir: A comparative study of anhydrous vs. monohydrate form microstructure and tabletting behaviour. Eur J Pharm Biopharm., 2006; 64:212-221.

Capellos C and BielskiBH.1972. Kinetic systems: mathematical description of chemical kinetics in solution. Wiley-Inter science, New York.

Deng J, Shao Y, Gao N, Deng Y, Tan C, Zhou S. Zero-valent iron/persulfate ( $\left.\mathrm{Fe}^{0} / \mathrm{PS}\right)$ oxidation acetaminophen in water. Int $J$ Environ Sci Technol., 2013; 11:881-890.

Diao MH and Yao MS. Use of zero-valent iron nanoparticles in inactivating microbes. Water Res., 2009; 43:5243-5251.

Dickinson M and Scott TB. The application of zero-valent iron nanoparticles for the remediation of a uranium-contaminated waste effluent. J Hazard Mater., 2010; 178:171-179.

Duan H. Study on the treatment process of wastewater from cephalosporin production. J Sustain Dev., 2009; 2:133-136.
Dyal A, Loos K, Noto M, Chang SW, Spagnoli C, Shafi KV, Ulman A, Cowman M, Gross RA. Activity of Candida rugosa lipase immobilized on gamma- $\mathrm{Fe}_{2} \mathrm{O}_{3}$ magnetic nanoparticles. J Am Chem Soc., 2003; 125:1684-1685.

Ghauch A, Tuqan A, Assi HA. Antibiotic removal from water; Elimination of amoxicillin and ampicillin by micro scale and nano scale iron particles. Environ Pollut., 2009;157:1626-1625.

Grigoriev P. Unified carrier-channel model of ion transfer across lipid-bilayer membranes. J Biol Phys Chem., 2002; 2:77-79.

Homem V and Santos L. Degradation and removal methods of antibiotics from aqueous matrices. J Environ Manage., 2011;92:23042347.

Hussaini A, Fisol FA, Yun LC, Hussain MH, Roslan HA. Lignocellulolytic enzymes produced by tropical white rot fungi during biopulping of Acacia mangium wood chips. J Biochem Technol., 2011; 3:245-250.

Kappeli O, Sauer M, Fiechter A. Convenient procedure for the isolation of highly enriched cytochrome P-450 containing microsomal fractions from Candida tropicalis. Anal Biochem., 1982; 126:179-182.

Kim JY, Park HJ, Lee C, Nelson KL, Sedlak DL, Yoon J. Interaction mechanism of Escherichia coli by nanoparticulate zero-valent iron and ferrous iron. Appl Environ Microbiol., 2010;76:76687670 .

Lee CH, Kim JY, Lee WI, Nelson K, Yoon JY, Sedlak D. Bactericidal effect of zero-valent iron nanoaparticles on Escherichia coli. Environ Sci Technol., 2008; 42:4927-4933.

Li Z, Greden K, Alvarez PJJ, Gregory KB, Lowry GV. Adsorbed polymer and NOM limits adhesion and toxicity of nano scale zero-valent iron to E. Coli. Environ Sci Technol., 2010; 44:3462-3467.

Li X, Elliot WL, Zhang W. Zerovalent iron nanoparticles for abatement of environmental pollutants: Materials \& engineering aspects. Crit Rev Solid State Mater Sci., 2006; 31:111-122.

Li Y, Xu X, Deng C, Yang P, Zhang X. Immobilization of trypsin on super paramagnetic nanoparticles for rapid and effective proteolysis. J Proteome Res., 2007; 6: 3849-3855.

Li Y, Du X, Wu C, Liu X, Wang X, Xu P. An efficient magnetically modified microbial cellbiocomposite for carbazole biodegradation. Nanoscale Res Lett., 2013; 8:522-524.

Mashelkar UC, and Renapurkar SD. A LCMS compatible stability-indicating HPLC assay method for cefdinir. Int JChem Tech Res., $2010 ; 2: 114-121$.

Oh SK, Kang SG, Chiu PC. Degradation of 2.4-dinitrotoluene by persulfate activated with zero-valent iron. Sci Total Environ., 2010; 408:2464-3468.

Okamoto Y, Kiriyama K, Namiki Y, Matsushita J, Fujioka M, Yasuda T. Degradation kinetics and isomerization of Cefdinir. A new oral Cephalosporin, in aqueous solution. 2. Hydrolytic degradation pathway and mechanism for $\beta$-lactam ring opened lactones. J Pharm Sci., 1996;85:984-989.

Ponder SM, Darab JG, Mallouk TE. Remediation of Cr(VI) and $\mathrm{Pb}$ (II) aqueous solutions using supported, nanoscale zero-valent Iron. Environ Sci Technol., 2000; 34:2564-2569.

RecekM and Raspor P. Yeast growth potential and COD reduction in waste water from ergot alkaloid production. Food Technol Biotech., 1999; 37:159-163.

Selvi A and Das N. Isolation, screening and identification of cefdinir degrading yeasts for the treatment of pharmaceutical wastewater. Int J Pharm Pharm Sci., 2014; 6:382-386.

Selvi A, Das D, Das N. Potentiality of yeast Candida sp. SMN04 for degradation of cefdinir, a cephalosporin antibiotic: Kinetics, enzyme analysis and biodegradation pathway. Environ Technol., 2015; 36: $3112-3124$.

Song C, Sheng L, Zhang X. Preparation and characterization of a thermostable enzyme (Mn-SOD) immobilized on supermagnetic nanoparticles. Appl Microbiol Biotechnol., 2012; 96:123-132.

Sun YP, Li XQ, Cao J, Zhang WX, Wang HP. A method for preparation of stable dispersion of zero-valent iron nanoparticles. Colloid Surface A: Physicochem Eng Aspects., 2007; 308:60-66. 
Vimala K, Sundarraj S, Paulpandi M, Vengatesan S, Kannan S. Green synthesised doxorubicin loaded zinc oxide nanoparticles regulates the Bax and Bcl-2 expression in breast and colon carcinoma. Process Biochem., 2014; 49:160-172.

Wang XH. and Lin AY. Phototransformation of Cephalosporin antibiotics in an aqueous environment results in higher toxicity. Environ Sci Technol., 2012; 46:12417-12426.

Wayne PA. 2002. National Commitee for Clinical Laborotory Standards (NCCLS). Performance standards for antimicrobial disk susceptibility testing. Twelfth informational supplement (M100-S12).

Wiesner MR, Lowry GV, Alvarez P, Dionysiou D, Biswas P. Assessing the risks of manufactured nanomaterials. Environ Sci Technol., 2006; 40:4336-4345.

Xu L, Guo C, Wang F, Zheng S, Liu C. A simple and rapid harvesting method for microalgae by in-situ magnetic separation. Bioresource Technol.,2011; 102:10047-10051.

Yalchin HT and Corbaci C. Isolation and characterization of amylase producing yeasts and improvement of amylase production. Turk $J$ Biochem., 2013; 38:101-108.

Yang $\mathrm{M}$ and Zheng S. Pollutant removal-oriented yeast biomass production from high-organic-strength industrial wastewater: A review. Biomass Bioenergy., 2014; 64: 356-362.
$\mathrm{Yu} \mathrm{Z}$ and Wen X. Screening and identification of yeasts for decolorizing synthetic dyeing industrial wastewater. Int Biodeterior Biodegrad., 2005; 56:109-114.

Zheng S. Zhang Y, Tong T, Cui C, Sun J. Dominance of yeast in activated sludge under acidic $\mathrm{pH}$ and high organic loading. Biochem Eng J., 2010; 52:282-288.

\section{How to cite this article:}

Selvi A, Das N. Nano-bio hybrid system for enhanced degradation of cefdinir using Candida sp. SMN04 coated with zero-valent iron nanoparticles. J App Pharm Sci, 2016; 6 (09): 009-017. 